\title{
Investigation of Climate Change Impact on Meteorological Data and Floods: A Case of Karacam, Turkey
}

\author{
Gokmen Ceribasi, Ahmet Iyad Ceyhunlu \\ Department of Civil Engineering, Faculty of Technology, Sakarya University of Applied Sciences, Sakarya, Turkey
}

\section{Email address:}

gceribasi@subu.edu.tr(G. Ceribasi), ahmetceyhunlu@subu.edu.tr (A. I. Ceyhunlu)

\section{To cite this article:}

Gokmen Ceribasi, Ahmet Iyad Ceyhunlu. Investigation of Climate Change Impact on Meteorological Data and Floods: A Case of Karacam, Turkey. Journal of Water Resources and Ocean Science. Vol. 9, No. 6, 2020, pp. 123-128. doi: 10.11648/j.wros.20200906.11

Received: November 2, 2020; Accepted: November 13, 2020; Published: November 27, 2020

\begin{abstract}
Turkey is among countries under influence of climate change as a result of global warming. These changes in climate cause large imbalances in temperature degrees and precipitation levels. While these imbalances in precipitation regimes cause drought in some regions, they cause sudden and severe precipitation in some regions. Therefore, in this study, effect of climate change on meteorological data and floods in Karacam region of Sakarya province was investigated. Meteorological data of the region used in this study was taken from General Directorate of Meteorology (DMI). Meteorological data are taken daily from station 17069 (10.01.2014 - 09.30.2019). Innovative Trend Analysis was used in analysis of meteorological data, and 2-dimensional flood propagation maps were obtained by using Hec-RAS software in flood analysis. As a result of analysis made, it was observed that climate change resulting from global warming has an impact on the meteorological data of Karacam region in Turkey, which is the study area. Because, it is observed that there is a generally downward trend in precipitation data, a generally increasing trend in temperature data and a decreasing trend in moisture data. Thus, impact of climate change can be clearly seen. Therefore, impact of this climate change shows not only an increase in temperatures and a decrease in precipitation, but also an increase in daily sudden and severe rains. For this reason, flood inundation maps of study area were created. Hec-RAS software was used to create flood propagation maps. As a result of these maps, it is seen that remain in floodplain of high-speed train line, agricultural lands and some of residential areas. Flood spreading maps of region have been created for sudden precipitation that may occur as a result of climate change and it has been observed that agricultural lands, residential areas and factories can be affected by this flood.
\end{abstract}

Keywords: Climate Change, Innovation Sen Method, Flood Analysis, Karacam, Turkey

\section{Introduction}

The hydraulic cycle, which is basic concept of water sciences, is defined as cycle of water in nature. As a result of an irregularity in this natural cycle of water, life of living things is affected by major disasters such as natural disasters. When causes of these natural disasters that have increased in recent years are investigated, it is observed that global warming and increasing population density are the most effective causes [1,2].

It is seen that effects of global warming increased its severity in $21^{\text {st }}$ century. As a result of global warming, climate changes cause large changes in precipitation regimes and temperature levels [3-5]. Investigating long-term forecasts of meteorological data for the future is one of the best methods for observe climate change impacts.
Trend analysis method is generally used in long term forecasting methods. Analysis method, one of new trend analysis methods in recent years and whose reliability has been revealed through academic studies, is an Innovative Trend Analysis [6].

In addition, changes in precipitation and temperature cause drought in some regions and sudden and heavy rainfall in other regions. Sudden and severe rains cause great floods with increase of urbanization. Although people's preference to live in areas close to water resources is successful in terms of meeting water needs, it affects their life activities negatively due to floods in excessive precipitation $[7,8]$.

Floods can be modeled by integrating as 1-dimensional or 2-dimensional or 1-dimensional and 2-dimensional [9]. 
Although 1-dimensional flood models are easy and practical, they make one-way calculations. When it comes to irregularities or a complicated flow in topography, it is seen that 1-dimensional calculations are insufficient and do not give correct results [10]. Recent studies have shown that more successful results are obtained if 2-dimensional flood models are installed, taking into account geometric and topographic features of study area instead of 1-dimensional flood models [11-20].

It is seen that floods are inevitable with increasing trend of global warming. Although it is not possible to prevent entire flood formation, it is possible to minimize its effects. In this study, effect of climate change on meteorological data and floods will be investigated in Karacam region of Sakarya in Turkey. Innovative Trend Analysis will be used in analysis of meteorological data, and 2-dimensional flood propagation maps will be obtained by using Hec-RAS software in flood analysis.

\section{Materials and Methods}

\subsection{Study Areas}

Karacam region is located in $40^{\circ} 38^{\prime} 34.9^{\prime \prime} \mathrm{N}-30^{\circ} 19^{\prime} 54.3^{\prime \prime} \mathrm{E}$ coordinates. Approximately 1,700 people live in the region. Karacam is $12 \mathrm{~km}$ from Sakarya city center and $20 \mathrm{~km}$ from Geyve district center. Location of Karacam region is given in Figure 1.

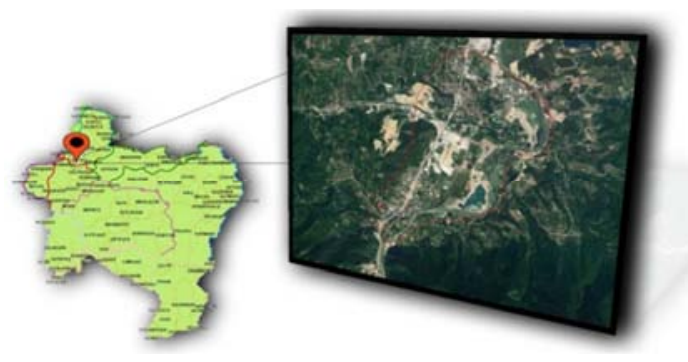

Figure 1. Location of Karacam.

Meteorological data of the region used in this study was taken from General Directorate of Metereology (DMI). Meteorological data are taken daily from station 17069 (10.01.2014 - 09.30.2019) and course line of these data (Precipitation, Temperature and Moisture) are given in figure 2 , figure 3 and figure 4 [21].

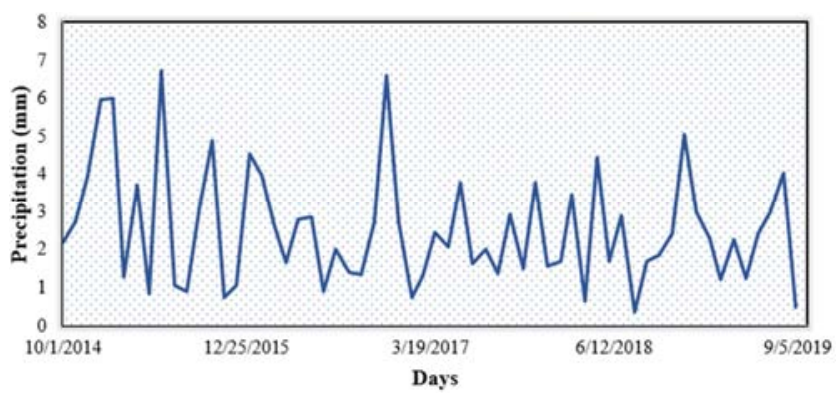

Figure 2. Precipitation Data of Sakarya Station.

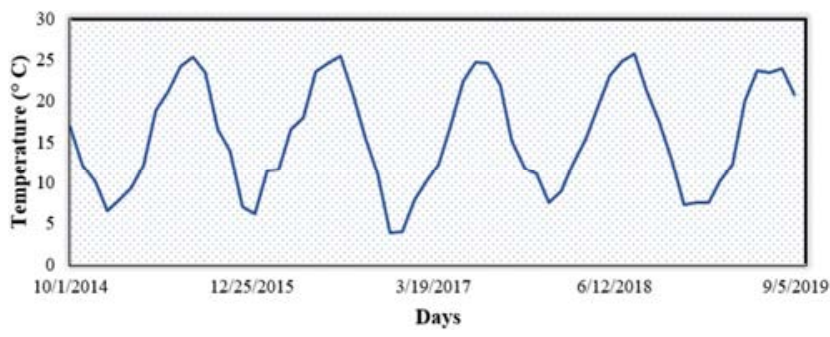

Figure 3. Temperature Data of Sakarya Station.

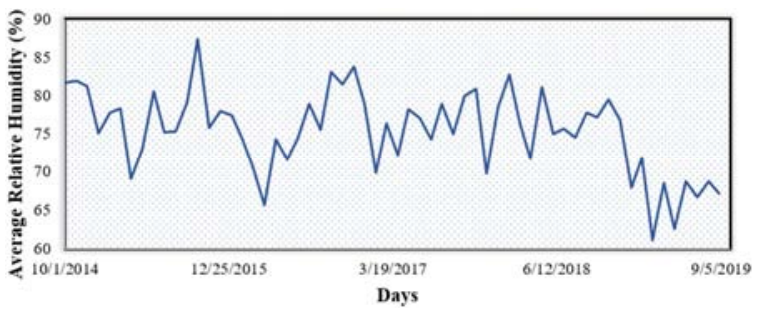

Figure 4. Moisture Data of Sakarya Station.

In addition, topographic maps of the region were taken from Directorate of Reconstruction and Urban Planning (DRUP). These data are arranged and shown in Figure 5 and Digital Elevation Model created by using Geographic Information System (GIS) software is given in figure 6 [22].

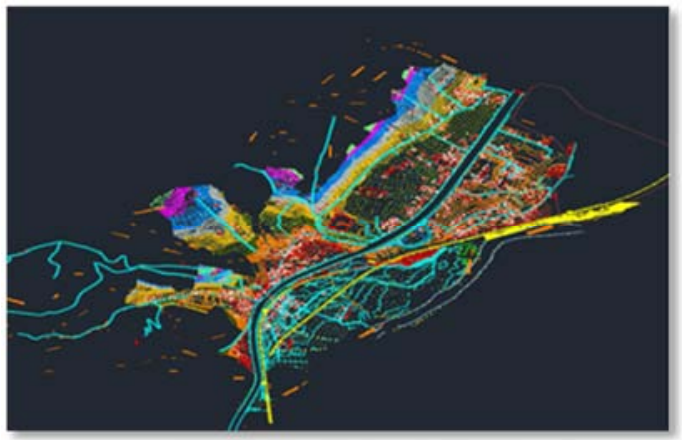

Figure 5. Base Map of Karacam.

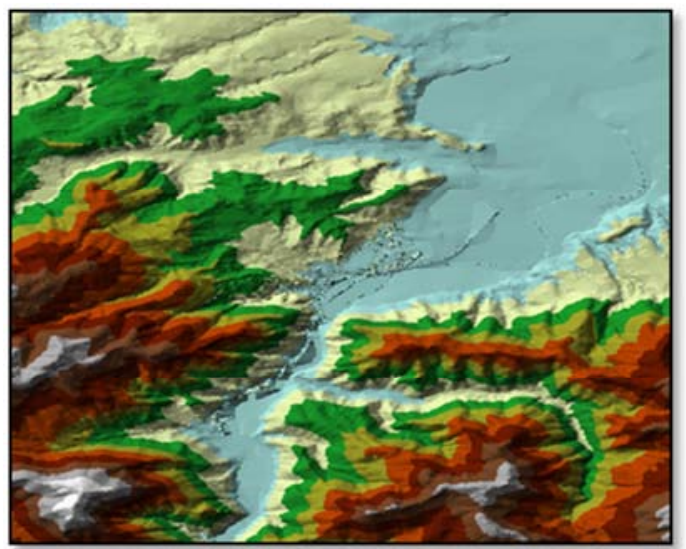

Figure 6. Digital Elevation Model of Karacam.

The 500-year recurring flood flow rate to be used in hydraulic modeling of this study area was taken from General Directorate of State Hydraulic Works (DSI). The $\mathrm{Q}_{500}$ hydrograph of this data is shown in figure 7 [23]. 


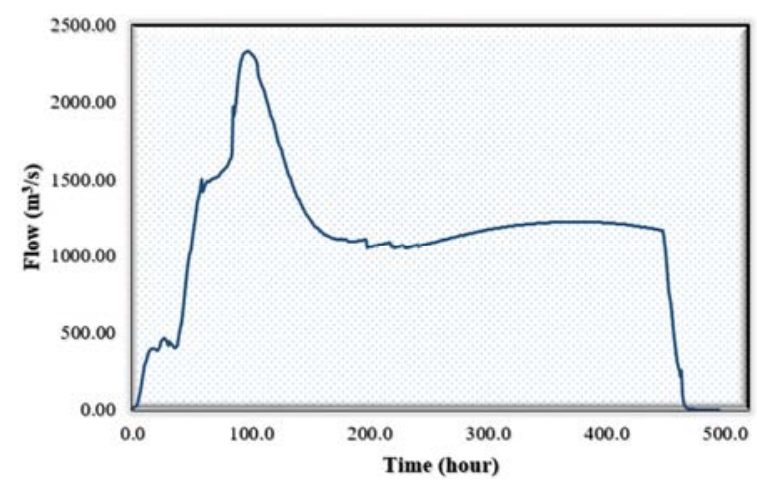

Figure 7. Hydrograph of $Q_{500}$.

\subsection{Innovative Trend Analysis}

Innovative Trend Analysis, one of new trend analysis methods in recent years and whose reliability has been revealed with academic studies, was first introduced by Sen [24]. With this method, Sen prevented some restrictive in other Trend Methods. Difference of Innovative Trend Analysis from Mann-Kendall and Spearman Rho Tests are dependent to time series and can analyze short data. In Innovative Trend Analysis, existing data is divided into two parts, exactly from middle. These two series are listed from small to large. First data series $\left(\mathrm{X}_{\mathrm{i}}\right)$ is placed on horizontal axis and second data series $\left(X_{j}\right)$ is placed on vertical axis on cartesian coordinate system. Arrangement of data in this way is included in Figure 8 [25-29].

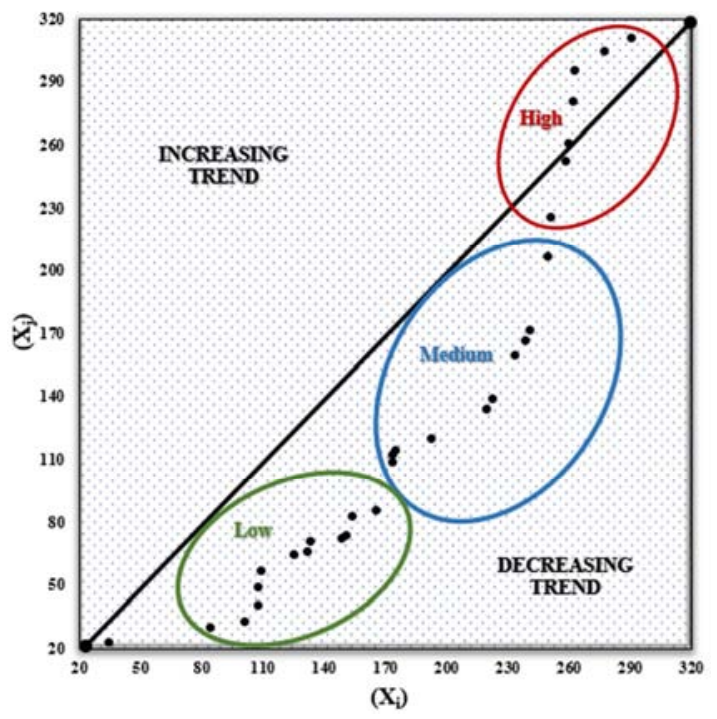

Figure 8. Illustration of Innovative Trend Analysis.

\subsection{D Modeling}

Hec-RAS software, which is the most widely used in 2dimensional flood modeling and has been proved by many academic studies, was produced and developed by USACE (United States Engineers Union Army). Hec-RAS software, which can calculate according to continuous currents or discontinuous currents in the creation of water face profiles, can perform unidirectional and bidirectional analyzes. In addition, Hec-RAS software has different submodules. In these modules can be made analyzes such as flood inundation maps, hydrological calculations and sediment transport. This software models using Saint-Venant equations for free surface currents. These equations are derived from the principles of continuity and conservation of momentum [30]. Figure 9 shows the steps to be followed during the creation of flood inundation maps.

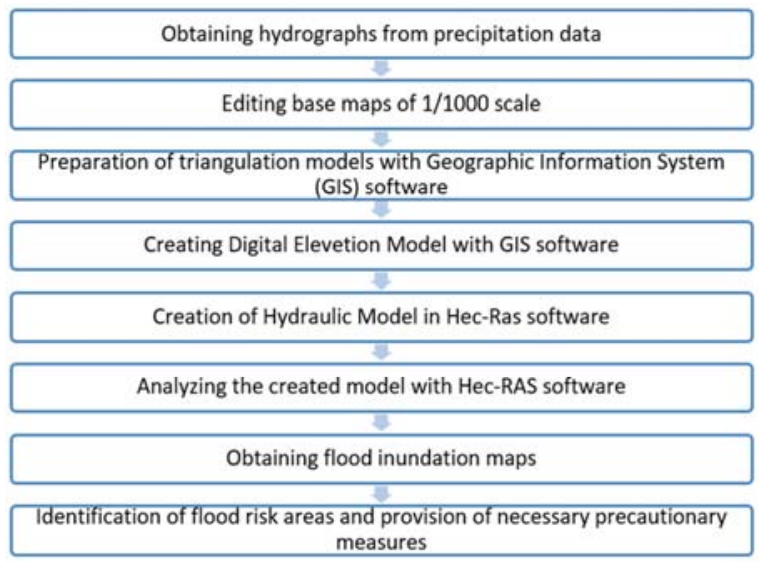

Figure 9. Preparation Stages of Flood Propagation Maps.

\section{Results and Discussion}

In this study, innovative trend analysis was applied to meteorological data of Karacam, which is the study area, to investigate climate change. In addition, flood inundation map of study area was created in 2-dimensions.

\subsection{Results of Innovative Trend Analysis}

Innovative Trend Analysis, one of Trend Analysis Methods, was applied to data of 1,826 days between 10.01.201409.30.2019 taken from station numbered 17069 in Sakarya province. Innovative Trend Analysis results applied to precipitation data are given in Figure 10.

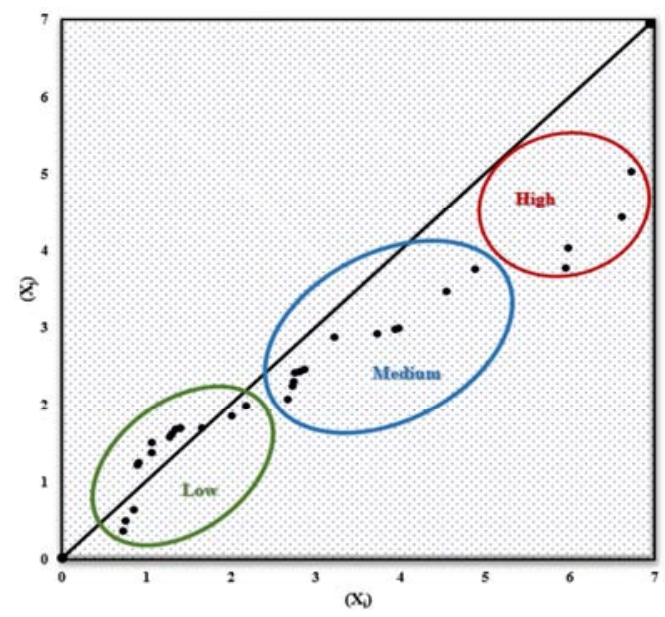

Figure 10. Results of Precipitation Data.

When results of analysis are analyzed, it is seen that there is a decreasing trend in precipitation data at medium and high levels. While at low levels, the data is above or very close to 
1:1 line and as a result, there is no trend at low levels. Innovative Trend Analysis results applied to temperature data are given in Figure 11.

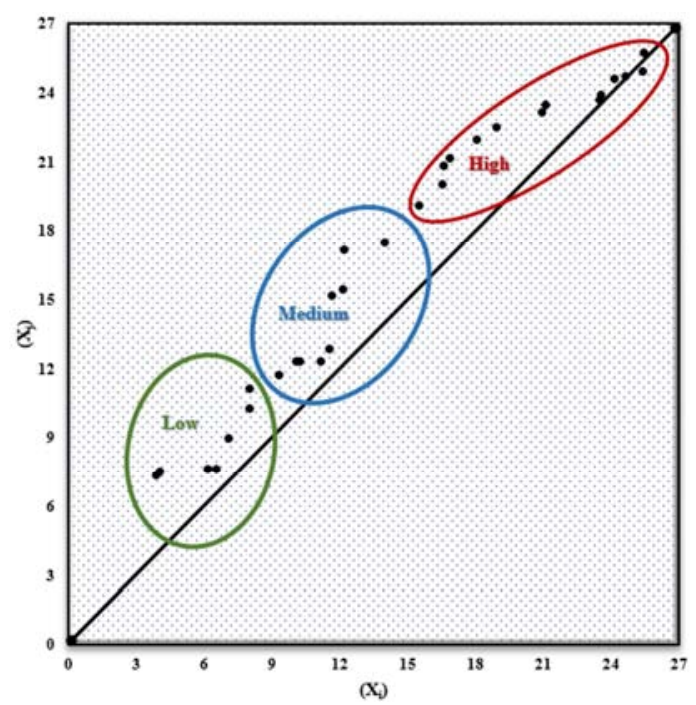

Figure 11. Results of Temperature Data.

When result of analysis is examined, it is seen that there is an increasing trend in temperature data at low, medium and high levels. Innovative Trend Analysis results applied to moisture data are given in Figure 12.

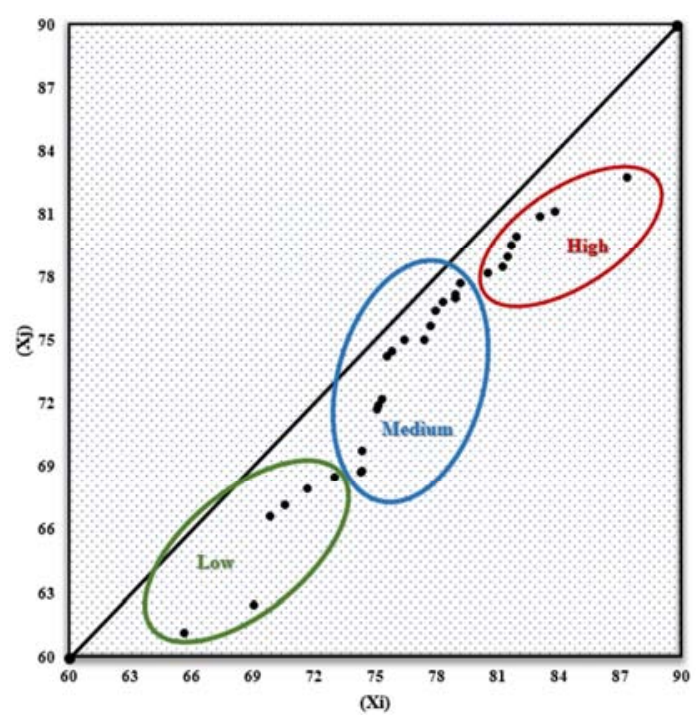

Figure 12. Results of Moisture Data.

When result of analysis is examined, it is seen that moisture data is a decreasing trend at low, medium and high levels. As a result of the study, general Innovative Trend Analysis results of meteorological data of Karacam region are given in Table 1.

When general results of innovative trend analysis are examined; It was observed that there was no 0-2 $\mathrm{mm}$ trend at low level in precipitation data, there was a trend decreasing between 3-5 $\mathrm{mm}$ at medium level and there was a decreasing trend between 3-9 $\mathrm{mm}$ at high level. It has been observed that there is an increasing trend in temperature data between 0 - $2^{\circ} \mathrm{C}$ at a low level, an increasing trend between $9-14^{\circ} \mathrm{C}$ at a medium level and an increasing trend between $16-26^{\circ} \mathrm{C}$ at a high level. It has been observed that there is a decreasing trend in moisture level between $65-74 \%$, there is a decreasing trend in the middle level of $75-80 \%$, and there is a decreasing trend between $81-90 \%$ in the high level.

Table 1. General Result of Innovative Trend Analysis.

\begin{tabular}{lccc}
\hline Parameter & Low & Medium & High \\
\hline Precipitation $(\mathrm{mm})$ & $0-2$ & $3-5$ & $6-8$ \\
Temperature $\left({ }^{\circ} \mathrm{C}\right)$ & $3-9$ & $9-14$ & $16-26$ \\
Moisture $(\%)$ & $65-74$ & $75-80$ & $81-89$ \\
\hline
\end{tabular}

\subsection{Results of 2-Dimensional Modeling}

In this study, Digital Elevation Model data prepared was transferred to Hec-RAS software and possible flood area was digitized in 2-dimensions. In addition, flow type was determined as unsteady flow and $\mathrm{Q}_{500}$ was analyzed with flood recurrence flow. Flood inundation map produced as 2dimensional in result of this analysis is given in Figure 13.

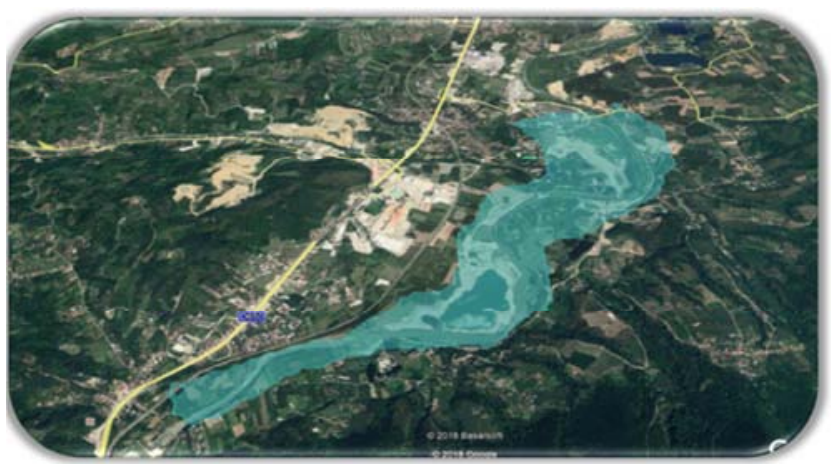

Figure 13. Flood Inundation Map of Karacam.

As a result of this analysis, flood inundation area in Karacam Region was calculated as 313 ha. From this flood, it was seen that agricultural lands in the region, 1 sand factory, 2 workplaces and 16 households were affected by flood.

\section{Conclusion}

In this study, long-term forecasts about future of meteorological events were made by considering global climate change. Long-term forecasts were obtained using Innovative Trend Analysis, one of Trend Analysis Methods. monthly average precipitation, monthly average temperature and monthly average relative moisture data taken from General Directorate of Meteorology were used.

As a result of analysis made, it was observed that climate change resulting from global warming has an impact on the metereological data of Karacam region in Turkey, which is the study area. Because, it is observed that there is a generally downward trend in precipitation data, a generally increasing trend in temperature data and a decreasing trend in 
moisture data. Thus, impact of climate change can be clearly seen. Therefore, impact of this climate change shows not only an increase in temperatures and a decrease in precipitation, but also an increase in daily sudden and severe rains. For this reason, flood inundation maps of study area were created. Hec-RAS software was used to create flood propagation maps. As a result of these maps, It is seen that remain in floodplain of high-speed train line, agricultural lands and some of residential areas.

It is extremely important to consider following recommendations to reduce impacts of climate change.

Minimizing use of fossil fuels that people consume unconsciously

Generating energy that is included in all daily needs from environmentally friendly and renewable sources

Increasing green residential areas that will decrease levels of greenhouse gases that increase as a result of industrialization and construction brought by increasing population

Creating awareness of protecting nature in them by giving correct trainings to future generations

In addition, channel reclamation work should be done for areas in flood area. appropriate cross section information and calculated by Manning equation is as follows.

Design as box cross section of stream bed

Cross section depth is $8 \mathrm{~m}$ and cross section width is $110 \mathrm{~m}$

Determination of Manning roughness coefficient as 0.03 and critical slope as 0.00058

If these parameters are applied, channel will pass tmaximum flow $\left(\mathrm{Q}_{500}\right)$.

\section{References}

[1] Mason, D. C., Guy, J. and Schumann, P. (2010). Flood Detection in Urban Areas Using Terrasar-X, IEEE $T$. Geoscience Remote, 48, 882-894.

[2] Rozalis, S., Morin, E., Yair, Y. and Price, C., (2010). Flash Flood Prediction Using an Uncalibrated Hydrological Model and Radar Rainfall Data in A Mediterranean Watershed Under Changing Hydrological Conditions, Journal of Hydrology, 394, 245-255.

[3] Sowmya, K., John, C. M. and Shrivasthava, N. K. (2015). Urban Flood Vulnerability Zoning of Cochin City, Southwest Coast of India, Using Remote Sensing and GIS, Natural Hazards, 75, 1271-1286.

[4] Akkaya, U. (2016). 2-Dimensional Flood Modelling of Maritza and Tundja Rivers at The Part of Edirne City Center: Sakarya University., Institute of Science, Published $\mathrm{PhD}$ Thesis, Sakarya.

[5] Akkaya U. And Dogan E. (2016). Generation of 2D Flood Inundation Maps of Meric and Tunca Rivers Passing Through Edirne City Center, Geofizika, 33 (1), 15-34.

[6] Dogan, E., Ceribasi, G., and Akkaya, U. (2016). Investigation for Effecting of Dam to River Flow Regime by Trend Analysis Method, Case Study of Sakarya River. Karaelmas Science and Engineering Journal. 6 (1), 50-55.
[7] Chuan, R. J. Y. (2006). An Empirical Analysis of Agricultural Products' Competitiveness and Complementarities Between China and ASEAN Countries. Journal of International Trade, 8.

[8] Gutry-Korycka, M., Magnuszewski, A., Suchozebrski, J., Jaworski, W., Marcinkowski, M., and Szydlowski, M. (2006). Numerical Estimation of Flood Zones in The Vistula River Valley, Warsaw, Poland, 308, 191.

[9] Horritt, M. S. and Bates P. D. (2002). Evaluation of 1d and 2d Numerical Models for Predicting River Flood Inundation, Journal of Hydrology, 268, 87-99.

[10] Huthoff, F., Remo, J. W. F. and Pinter, N. (2015). Improving Flood Preparedness Using Hydrodynamic Levee-Breach and Inundation Modelling: Middle Mississippi River, Usa, Journal of Flood Risk Management, 8, 2-18.

[11] Djokić, S. S., Conway, B. E., and Belliveau, T. F. (1994). Specificity of Anodic Processes in Cyclic Voltammetry to The Type of Carbon Used in Electrolysis of Cryolite-Alumina Melts. Journal of Applied Electrochemistry, 24 (9), 827-834.

[12] Correia, A., and Šafanda, J. (1999). Preliminary Ground Surface Temperature History in Mainland Portugal Reconstructed from Borehole Temperature Logs. Tectonophysics, 306 (34), 269-275.

[13] Mclin, S. G., Springer, E. P., and Lane, L. J. (2001). Predicting Floodplain Boundary Changes Following The Cerro Grande Wildfire. Hydrological Processes, 15 (15), 2967-2980.

[14] Aggett, G. R., and Wilson, J. P. (2009). Creating and Coupling A High-Resolution DTM with A 1-D Hydraulic Model in A GIS for Scenario-Based Assessment of Avulsion Hazard in A Gravel-Bed River. Geomorphology, 113 (1-2), 21-34.

[15] Cook, A. and Merwade, V. (2009). Effect of Topographic Data, Geometric Configuration and Modeling Approach on Flood Inundation Mapping, Journal of Hydrology, 377, 131-142.

[16] Vojinovic, Z. and Tutulic, D. (2009). On The Use of 1D and Coupled 1D-2D Modelling Approaches for Assessment of Flood Damage in Urban Areas. Urban Water Journal, 6 (3), 183-199.

[17] Amini, J. (2010). A Method for Producing Flood Maps Using IKONOS Images and Dems. International Journal of Remote Sensing, 31 (9), 2441-2456.

[18] Gumrukcuoglu, M., Goodin, D. G., and Martin, C. (2010). Landuse Change in Upper Kansas River Floodplain: Following The 1993 Flood. Natural Hazards, 55 (2), 467-479.

[19] Hung, N. N., Delgado, J. M., Tri, V. K., Hung, L. M., Merz, B., Bárdossy, A., and Apel, H. (2012). Floodplain Hydrology of The Mekong Delta, Vietnam. Hydrological Processes, 26 (5), 674-686.

[20] Hajibayov, F., Ozkul, B. D., and Terzi, F. (2017). Floodplain Modeling and Mapping Using The Geographical Information Systems (GIS) And Hec-RAS/Hec-Georas Applications. Case of Edirne, Turkey. GISRUK.

[21] Meteorological Datas of State Meteorology Affairs (DMI). (2019). Rainfall, Temperature and Moisture Datas.

[22] Directorate of Reconstruction and Urban Planning (DRUP). (2019). Topographic Maps.

[23] General Directorate of State Hydraulic Works (DSI). (2019). Streamflow Datas. 
[24] Kisi, O., Santos C. A. G., da Silva, R. M and ZounematKermani, M. (2018). Trend Analysis of Monthly Streamflows Using Sen's Innovative Trend Method, Geofizika, 35 (1), 53 68 .

[25] Sen, Z. (2012). Innovative Trend Analysis Methodology. Journal of Hydrological Engineering, 17 (9), 1042-1046.

[26] Sen, Z. (2013). Trend Identification Simulation and Application. Journal of Hydrological Engineering, 19 (3), 635-642.

[27] Ceribasi, G. and Dogan, E. (2015). Evaluation of Streamflow of West and East Black Sea and Sakarya Basin by Using Trend Analysis Method. Suleyman Demirel University International Technologic Science, 7 (2), 1-12.
[28] Ceribasi, G. and Dogan, E. (2016). Application of Trend Analysis Method on Rainfall-Stream Flow-Suspended Load Data of West and East Black Sea Basins and Sakarya Basin, Fresenius Environmental Bulletin, 25, 300-306.

[29] Ceribasi, G. (2019). Analyzing Rainfall Data's of Eastern Black Sea Basin by Using Sen Method and Trend Methods. Journal of The Institute of Science and Technology, 9 (1), 254-264.

[30] Samandar, A., Genc, O. (2016). Creating Floodplain Maps Based on The Geographic Information Systems in Duzce Buyuk Melen Stream, Journal of Advanced Technology Sciences, 5 (2), 184-189. 